\title{
Narrativas transmediáticas en la apropiación social del conocimiento
}

\section{Transmedia storytelling in the social appropriation of knowledge}

\author{
Ariadna Jauregui Caballero. Universidad Autónoma del Estado de México. México. \\ ajaureguic@uaemex.com \\ $[\mathrm{CV}] \mathrm{R}^{\mathrm{i}}$ \\ Claudia Ortega Ponce. Universidad Autónoma del Estado de México. México. \\ cop@uaemex.mx \\ $[\mathrm{CV}] \overline{\mathrm{G}} \mathrm{R}^{\circ}$
}

\author{
Cómo citar este artículo / Referencia normalizada \\ Jauregui Caballero, A. y Ortega Ponce, C. (2020). Narrativas transmediáticas en la apropiación \\ social del conocimiento. Revista Latina de Comunicación Social, (77), 357-372. \\ https://www.doi.org/10.4185/RLCS-2020-1462
}

\begin{abstract}
RESUMEN
Los medios de comunicación a partir de la implementación de las nuevas Tecnologías de la Información y Comunicación (TIC) se han diversificado conforme a la evolución y adaptación del uso de dispositivos tecnológicos en la vida del hombre. Con la hibridación de los medios surge la ecología mediática en la cual emergen nuevas formas de llevar acabo el acto comunicativo, los medios de comunicación se adaptan a la prácticas comunicativas y en ello se condensan las nuevas formas de comunicar. Estudiar el alcance y los niveles significativos de los modelos convergentes en los procesos de comunicación digital no sólo nos acercan al panorama mediático también nos vislumbra las capacidades de las plataformas y los dispositivos en el contexto social. En el siguiente documento discutiremos como a partir de la implementación de herramientas digitales y las narrativas transmedia podemos generar un aporte significativo a la apropiación del conocimiento por parte de los usuarios. Mediante el reconocimiento de los niveles de significación de todos los actores involucrados en la comunidad, entenderemos como las dinámicas participativas y colaborativas nos acercan a la democratización del conocimiento. Para comprender tanto el proceso apropiación del conocimiento como la relación que existe entre la sociedad y la tecnología es necesario definir de manera conceptual el proceso de apropiación, posteriormente el ecosistema mediático en el que se vinculan la narrativas mediáticas, para así abordar la relación que existe entre la tecnología digital, las narrativas transmedia y los procesos de apropiación del conocimiento en los usuarios.
\end{abstract}

PALABRAS CLAVE: comunicación digital, narrativas transmedia, apropiación social del conocimiento, TIC.

\begin{abstract}
The implementation the new Information and Communication Technologies (ICT) have diversified the media, according to the evolution and adaptation of the use of technological devices in human life. With the hybridization of the media, the media ecology arises in which new ways of carrying out the communicative act emerge, with this the media adapts to communicative practices and are condensed in this new ways of communicating. Studying the scope and significant levels of convergent models in digital communication processes not only bring us closer to the media
\end{abstract}


landscape, also glimpse the capabilities of platforms and devices in the social context. In the following document we will discuss how the implementation of digital tools and transmedia narratives can generate a significant contribution to the appropriation of knowledge by users. Recognize the levels of significance of all the actors involved in the community, allows us to understand how participatory and collaborative dynamics bring us closer to the democratization of knowledge. To understand both the process of appropriation of knowledge and the relationship that exists between society and technology, it is necessary to define the process of appropriation in a conceptual way, the media ecosystem in which the media narratives are linked and the relationship that exists between digital technology, transmedia narratives and the processes of appropriation of knowledge in users.

KEYWORDS: digital communication, transmedia narratives, social appropriation of knowledge, ICTs.

\section{CONTENIDOS}

1. Metodología. 1.1. La apropiación social del conocimiento como parte fundamental para el desarrollo social. 1.1.1. El proceso de apropiación social del conocimiento. 1.1.2. Relación tecnología y sociedad. 1.2. El ecosistema mediático digital. 1.2.1. Elementos conceptuales que definen a las narrativas transmediáticas. 1.2.2. Narrativas transmediáticas como herramientas para fortalecer la apropiación social del conocimiento. 2. Conclusiones. 3. Referencias.

\section{Metodología}

El siguiente documento es un análisis exploratorio desde la literatura y los conceptos que engloban el proceso de comunicación de la ciencia en específico en el área de la divulgación científica mediante las definiciones: apropiación social del conocimiento, narrativas transmedia y la comunicación digital interactiva.

Primeramente se pretende hacer un dialogo entre autores que retoman la apropiación social del conocimiento como parte de la actividad humana y como una herramienta de democratización de la información para la mejora de la calidad de vida de la sociedad.

Posteriormente se hace un acercamiento analítico a la relación sociedad y tecnología donde se busca destacar cuales son las capacidades y cualidades inmersos en ella y a su vez las características que engloban la ecología mediática en la cual se construye.

Al conceptualizar la apropiación social del conocimiento y reconocer la relación que se establece entre la sociedad y la tecnología el documento busca hacer un aporte teórico a partir de las narrativas transmedia, las cuales como herramientas de significación pueden permear hacía la apropiación social del conocimiento de manera relevante.

\subsection{La apropiación social del conocimiento como parte fundamental para el desarrollo social}

La apropiación social del conocimiento implica que existan canales que fortalezcan la democratización al acceso y uso del conocimiento. Su adecuada transmisión y aprovechamiento entre los distintos actores sociales derivará en la implementación de estrategias que mejoren de la calidad de vida de las comunidades y sus integrantes. 
Para que existan canales de fortalecimiento de la apropiación del conocimiento es necesario reconocer las necesidades de los usuarios y el proceso que se encuentra inmerso en las actividades que motiven los niveles de significación por parte los usuarios.

A continuación definiremos el proceso de apropiación social del conocimiento y sus aproximaciones conforme al desarrollo y fortalecimiento dentro una sociedad informada.

\subsubsection{El proceso de apropiación social del conocimiento}

La apropiación social del conocimiento reconoce que los sectores sociales deberán usar intensamente la información y conocimiento disponibles para reconocer cuales son los procesos de experimentación y aprendizaje que se relacionan con los mecanismos de apropiación. Esto permite darle al público no especializado los medios para que se forme una opinión sobre las prácticas que afectan su vida cotidiana, generando una opinión participativa con más conocimiento y responsabilidad (Vessuri, 2002).

Para que exista una apropiación significativa del conocimiento es necesario que se faciliten canales de interacción generado por las investigaciones en manos de los investigadores, productores de contenidos y tecnólogos; a su vez también es necesario estimular la propia apropiación mediante el reconocimiento de las capacidades de los usuarios en un sentido más democrático, esto permitirá que las prácticas propias que se establecen en el proceso de comunicación de la ciencia se diversifiquen, tengan mayor apertura y alcance.

Vessuri afirma que cuando la ciencia aparece en los medios, sucede como un tema destinado al consumo masivo sin un contexto crítico; ocurre como la narración de una acumulación de hechos científicos lo que provoca la descontextualización de la información a partir de un reduccionismo que refleja agendas ocultas, que por resultado no informa ni mejora la comprensión social de la ciencia (Vessuri, 2002).

En este sentido a partir de las oportunidades que brindan las TIC la transmisión del conocimiento puede verse favorecida como medio de acceso y distribución por medio de los dispositivos digitales; para ello deberán de visibilizarse las barreras que impiden el acceso y reutilización de la información derivada de la actividad (Melero, et. al., 2014).

Al tener conocimiento acerca de los niveles de apropiación y significación de la información que los usuarios disponen sobre las investigaciones científicas se puede obtener una panorama el cual se acerque a la percepción que tiene la sociedad sobre la ciencia, permitiendo posteriormente fortalecer canales accesibles de participación en la formulación del conocimiento.

\subsubsection{Relación tecnología y sociedad}

La evolución de los dispositivos tecnológicos ha posibilitado diferentes niveles de conexión donde se crean nuevos espacios de interacción, en estos espacios se llevan diversas dinámicas de transferencia como parte de la comunicación humana y su relación con su entorno cotidiano.

La relación que establece la sociedad a partir del uso de la tecnología repercute en varios ámbitos de la vida social, cultural y económica del hombre, esto transforma las modalidades de comunicación entre personas y a su vez propicia al desarrollo de herramientas específicas con aplicación en campos como lo son la educación, la administración, la salud, el trabajo, comercio (Sánchez, et. al., 2012). 
La relación entre tecnología y sociedad y la transferencia de información que existe en ella visibiliza una serie de posibilidades y aplicaciones, en la actualidad nos encontramos con amplio abanico de opciones tecnológicas pero es sólo a través de la relación que se establece en la esfera social que la los dispositivos tecnológicos toman auge e importancia en la cotidianidad de los usuarios.

\subsection{El ecosistema mediático digital}

Con el surgimiento de las nuevas tecnologías la discusión que surge entre los medios tradicionales de la comunicación (impresos, radio y televisión) y los nuevos medios digitales (plataformas online y dispositivos electrónicos con acceso a Internet) suponía la superioridad de uno sobre otro inclusive la extinción del alguno, la realidad es que los medios de comunicación resultan útiles tanto que la sociedad los asuma necesarios, es por ello que la convergencia mediática ha resultado con el paso de los años una herramienta con múltiples fines instrumentales para la estructura social.

El auge y desarrollo tecnológico propició la aparición de nuevas prácticas cotidianas; los medios de comunicación son comprendidos como instrumentos, herramientas y tecnologías que el ser humano incorporó en su relación con ambiente, convirtiéndolas en extensiones de su cuerpo (McLuhan, 1998).

La sociedad no necesita adaptarse a las características de las nuevas tecnologías, resulta mucho más importante que las tecnologías deban adaptarse a las verdaderas necesidades del ser humano (Morin, 2000). Los medios deberán adaptarse a este nuevo escenario mediante la articulación de ecosistemas comunicativos que les permitan integrar más de una plataforma para diversificar sus canales y, especialmente, para amplificar el alcance de sus mensajes (Calvo, et. al., 2018).

La relación entre sociedad y medios de comunicación es un ámbito de estudio bastante amplio y con múltiples aportaciones a los estudios sociales en la comunicación ${ }^{1}$, la importancia del discurso y su codificación en el contexto social por medio de la interacción con los dispositivos digitales nos acerca a un modelo de comunicación digital por medio de la reflexión de los alcances y limitaciones del mismo.

La tecnología digital posibilita el consumo bajo demanda de contenidos audiovisuales y, además, el usuario puede beneficiarse de las diversas formas de difusión de los contenidos, optando por pantallas alternativas. Todos estos nuevos hábitos de consumo audiovisual multipantalla contribuyen a crear y consolidar el moderno estilo de vida digital (Scolari, 2012).

El proceso de convergencia con el ecosistema mediático involucra a los propios de los medios convencionales (contenidos estandarizados, coste por acceso, consumo individualizado pasivo) y los medios característicos de la Web Social (contenidos personalizados y/o generados por el usuario, entornos abiertos a terceras partes, trabajo colaborativo, predominio de la cultura de la compartición) (Aguado \& Martínez, 2009).

\footnotetext{
${ }^{1}$ El desarrollo de los estudios de comunicación se ha visto marcado por hechos que rebasan la dinámica propia de las disciplinas que lo integran: por una parte lo reciente de su constitución como campo académico y la fuerte incidencia de la revolución tecnológica en la conformación y acelerada transformación de sus objetos de estudio, y por otra la constante interacción entre las variaciones sociales, los cambios culturales y políticos y las modificaciones que en una perspectiva histórica iban teniendo las comunicaciones en el mundo y en el país [...]El campo de la comunicación se forma así en América Latina del movimiento cruzado de dos hegemonías: la del paradigma informacional/instrumental procedente de la investigación norteamericana, y la del paradigma crítico / ideológico en las ciencias sociales latinoamericanas (MartínBarbero \& Rey, 1999, pp. 54-70).
} 
La diversidad mediática implica comprender las relaciones que surgen a partir del uso de los dispositivos por parte de los usuarios interactuando con otros usuarios, para Islas-Carmona (2015) estudiar el ecosistema mediático involucra abordar la complejidad desde el análisis de su organización sistémica; esto desde de los cambios que se producen con la incorporación de nuevas las tecnologías y los medios de comunicación en las sociedades a lo largo de la historia.

Reconocer el papel que juegan los medios en la construcción de un ecosistema mediático nos acerca a entender las características de los mismo dentro del proceso de comunicación digital, siendo los usuarios los únicos capaces de llevar a cabo la socialización por medio de estos ecosistemas mediáticos.

Los cibermedios forman parte del surgimiento de las TIC vinculadas por medio de la digitalización cibernética, Para Cebrián Herreros la concepción de los cibermedios se entiende de la siguiente manera:

...parte de un proceso donde el productor/emisor de contenidos y servicios informativos mediante estrategias y técnicas periodísticas específicas y adecuadas a las exigencias de la plataforma Internet y con la potencialidad incorporada por ésta como el uso integrado de varios sistemas expresivos: escrito, gráfico, icónico, auditivo, audiovisual y multimedia, hasta llegar a unos usuarios que pueden seguir, manejar o producir otras informaciones y entablar diálogo o intercambiarse los papeles con el emisor. Se parte, pues, de una concepción de los cibermedios como procesos diferentes a los de los medios de comunicación tradicionales. No obstante, no se plantean como radicalmente opuestos, sino que se establecen diversas vinculaciones entre unos y otros. (Cebrián Herreros, 2009, p. 16)

La diversificación de los elementos que constituyen el proceso de comunicación por medio de multimedialidad $^{2}$ de los dispositivos sugiere el estudio de la capacidad de aplicación de las nuevas tecnologías en el proceso de socialización y de producción por medio de las estructuras sociales en la comunicación digital.

A partir del estudio de las TIC se generan nuevos conocimientos que nos llevan a descubrir cuál es la importancia que tienen en la vida diaria y lo que significan en para los usuarios. Yepes afirman que el lenguaje comunicativo desde el punto de vista digital, organiza y reestructura la información por medio de un sistema de redes que controlan la interacción de los usuarios; al estudiar los sistemas digitales de comunicación se reconoce una nueva sociedad de la información, esto permite entender el papel de las tecnologías y su aplicabilidad en diferentes ámbitos sociales (Yepes, 2011).

Los estudios sobre la comunicación digital parten del estudio de las TIC en sociedad, han aportado un valor significante al estudio de la codificación del mensaje desde el uso de

\footnotetext{
${ }^{2}$ El desarrollo multimedia se define como una nueva forma de crear aplicaciones en las que tienen cabida conceptos como el sonido, el video, la música, la interactividad, el diseño gráfico, etc. [...] Multimedia es la combinación de textos, gráficos, sonido, animación y video para lograr una presentación (Iznaola, 2005).
} 
dispositivos tecnológicos, desde la diversificación de plataformas hasta el surgimiento de nuevos espacios interactivos como el ciberespacio. Un mensaje puede tener varias formulaciones que derivan de los dispositivos, para los actores los dispositivos se vuelven extensiones en tanto su uso propicie la interacción y la vinculación con otros actores, en este caso los dispositivos digitales son una forma de extensión de la interacción humana. Las plataformas virtuales en si son un espacio de interacción social. El usuario deja de ser sólo receptor de información, un consumidor sedentario de los medios tradicionales, y adopta un papel activo frente una oferta completa y heterogénea de contenidos que él mismo puede seleccionar según sus necesidades (Jódar, 2010).

La revolución digital posee una mayor intensidad, esta es capaz de desplazar el universo cultural de una sociedad hacia formas de producción, distribución y comunicación mediatizadas por los dispositivos tecnológicos. La comunicación digital tiene características generales propias de su proceso de codificación del lenguaje, Manovich categoriza estas características a partir de los nuevos procesos de producción de la información:

A. La representación numérica o digitalización: Consiste en la codificación a partir de algoritmos numéricos de la información para ser almacenada y transmitida por medio de aparatos digitales, en esta característica el término información juega capacidades ambiguas dependiendo del análisis de los factores informáticos o comunicativos.

B. La modularidad: es parte de una estructura mayor, la cual se muestra discreta y se fractura según se diversifiquen los medios.

C. La variabilidad: el mensaje al igual que los medios se presenta en una visión fragmentada y particularizada por las características de la interacción y el uso de la tecnología.

D. La automatización: desde la creación, manipulación y acceso a la información.

E. La transcodificación: interceden agentes no humanos en los procesos de comunicación, estos con estructuras propias pero que son mediados a partir de las convenciones humanas. (Manovich, 2005, pp. 64-72)

Manovich reconoce que los dispositivos digitales forman parte de nuevos procesos de transcodificación del mensaje generando nuevos contextos y espacios de interacción del proceso comunicativo como tal. La fragmentación del mensaje se ve mediada por las características de los dispositivos tecnológicos lo que implica comprender cuales son los elementos de la comunicación digital como tal.

La discusión sobre los aportes sociales de los dispositivos tecnológicos en la vida de los usuarios en comunicación es bastante amplia y compleja, es importante considerar que analizar la comunicación digital como parte de un proceso mayor necesita precisar en los elementos que la caracterizan y los factores que determinan su funcionamiento. 


\subsubsection{Elementos conceptuales que definen a las narrativas transmediáticas}

En el proceso de comunicar el relato existe un esfuerzo significativo de estructuración del pensamiento y reflejado en el habla a través de las historias, los individuos constantemente relatamos el suceso como una actividad que sustenta la trascendencia del mismo. Para ello es necesario darle una continuidad al relato, una sucesión de hechos los cuales retroalimentan el sentido de la historia y le permiten a los individuos conectarse a la raíz del significado.

Dicha continuidad puede ser planeada por emisor de manera inicial pero también puede ser el fruto de la reorganización operada por la apropiación de los individuos que interactúan con el relato, esto supone una recontextualización de la historia y le da un nuevo valor significante para todos los actores inmersos en el mismo (Carrera, 2013).

Con el surgimiento de nuevos dispositivos y plataformas para llevar a cabo el proceso de comunicación humana el relato adoptó características que le permiten aumentar los niveles de interacción y a su vez la contextualización del mensaje, estas características se atribuyen al uso de los sentidos, la permanencia de los usuarios con respecto al acto comunicativo y la temporalidad en la cual se cuenta la historia.

Pratten describe que existe un nivel de concordancia entre la capacidad de participación que tiene el usuario conforme a los niveles de interacción que se ejercen dentro su experiencia en cada plataforma, entre mayor sea la participación en una plataforma por medio de experiencias sociales se incrementan los niveles de significación del mensaje:

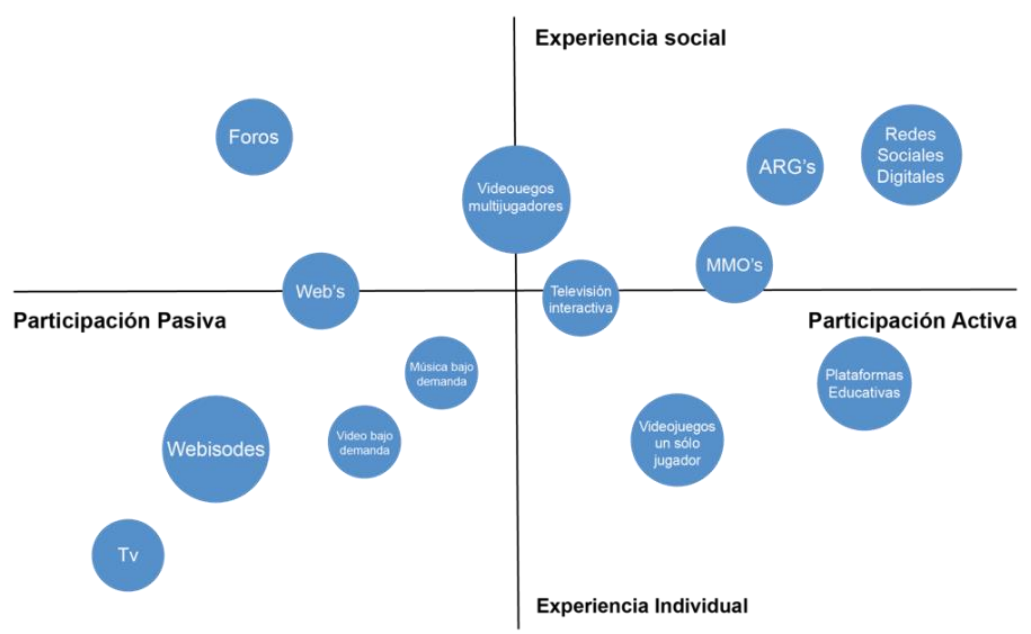

Gráfico 1: niveles de participación y experiencia de los usuarios digitales.

Fuente: (Pratten, 2011).

La tecnología digital ${ }^{3}$ juega hoy en día un papel importante en la transmisión de la información y en la construcción narrativa de los sucesos cotidianos, su implementación ha abierto nuevos canales de comunicación. Freitas y Castro responden que el desarrollo tecnológico juega un papel importante en la generación de nuevos contenidos:

\footnotetext{
${ }^{3}$ Técnicas implantadas por la etapa digital donde se constituyen un conjunto de tecnologías cuyas aplicaciones abren un amplio abanico de posibilidades a la comunicación humana. Las telecomunicaciones pierden su carácter autónomo e independiente a favor de la flexibilidad, y las antiguas parcelaciones tecnológicas autónomas se disuelven haciéndose obligatorios los contactos y las colaboraciones multidisciplinares (Jórdar, 2010).
} 
El paso del mundo analógico al digital ofrece la oportunidad de desarrollar contenidos con múltiples relatos, con historias paralelas interactivas y relacionadas entre sí. Un relato que el hombre occidental busca desde hace tiempo en la elaboración de la mirada sobre sí mismo, en la construcción de una visión personalizada de la historia. (Freitas y Castro, 2010, p. 22)

El concepto de narrativa digital tiene varias directrices que se apoyan tanto en el desarrollo tecnológico de los medios de comunicación como en la apropiación de los usuarios de nuevas técnicas y lenguajes digitales. Phillippi y Avedaño (2011) consideran a la narrativa digital como una nueva forma de contar la historia donde se configura el valor estético por medio de las tecnologías digitales de la comunicación gracias al uso del hipertexto, donde se adoptan las palabras, imágenes, sonido y videos buscando promover la lectura multilineal y multisecuencial lo cual permite que tanto productores como usuarios interactúen en diversos espacios digitales.

Las narrativas digitales no se alejan de las formas anteriores de relatar es a partir de ellas formulan nuevas las normas y criterios en el lenguaje audiovisual para así establecer el sentido pragmático del mensaje. Esto implica el uso de representaciones icónicas del lenguaje donde el usuario retoma estas representaciones y las asume de manera significativa lo cual a su vez permite la reconfiguración del mensaje:

La convergencia online y offline ha cambiado la forma de consumir los medios de comunicación y ahora los creadores de contenido y desarrolladores web pueden trabajar juntos para conseguir un enfoque integral, interconectado y con una nueva experiencia interpretativa. La audiencia sigue muchos espacios informativos o de entretenimiento utilizando segundas pantallas (el móvil, un ordenador, el iPad u otro tipo de tablet) y lo hacen visualizando el programa, enviando twitt a sus seguidores o participando directamente con la dirección de la historia. (Saíz, 2016, p. 14)

La construcción del discurso en las narrativas digitales depende tanto de la producción del mensaje como de la participación de la audiencia la cual le da la capacidad de extenderse, a través de distintas plataformas digitales. Con la comunicación digital el vínculo del contenido con el receptor llega mediante vías alternativas de transmisión es decir la imagen, el audio y las expresiones literarias se visualizan de manera electrónica.

Entonces las narrativas digitales son un objeto virtual, este se construye con técnicas estéticas y se significa a partir de las dinámicas de interacción por medio del uso sensorial y la convergencia de múltiples plataformas. En ellas los sujetos tienen posibilidades de recibir y generar propuestas de sentido, a partir de la utilización de diversos dispositivos lo cual les permite ser capaces de generar relatos lo cual los vincula a en las temáticas mejorando su propia experiencia como la de otros (Phillippi y Avedaño, 2011).

Las narrativas digitales tienen como objetivo fomentar la colaboración creativa por parte de los usuarios, esta práctica no era particularmente propia de la lógica analógica; en la lógica multimedial 
se busca que los usuarios sean participativos con la generación y transmisión de los contenidos lo que reformula la función del mensaje a partir de la organización tanto de autores, como productores y usuarios (Freitas y Castro, 2010).

Basándose en un modelo colaborativo las narrativas digitales buscan que los autores (responsables de la intelectualidad de la obra) por medio de los productores (responsables de vincular el contenido por medio de las plataformas) y los usuarios (quienes consumen el contenido) tengan la capacidad de establecer una lógica interactiva en la cual los roles puedan intercambiarse según la dinámica de las plataformas, los dispositivos y los canales de comunicación.

En este sentido el lenguaje audiovisual permite construir las representaciones de la realidad con las cuales se postula el valor significativo esto favorece la conectividad y por ende promueve la interacción. El lenguaje audiovisual, el uso de múltiples plataformas, las nuevas formas de interacción digital y el uso de narrativas múltiples, permite que la apropiación del mensaje se manifieste de formas significativas y aumenten los niveles de conectividad entre los autores, los productores y los usuarios.

Con la hibridación de los géneros narrativos ${ }^{4}$ y los diversos formatos digitales ${ }^{5}$ se pueden tener un acercamiento a los cambios que posibilitan nuevos valores estéticos, semióticos y pragmáticos.

A continuación desglosaremos dos conceptos que abordan la construcción del mensaje a partir del uso de las narrativas digitales, donde el lenguaje audiovisual juega un papel importante en la valoración y significación tanto de los usuarios como los productores.

El uso narrativo del lenguaje audiovisual permite la construcción del discurso con respecto a las características del contexto explícito en el cual se encuentra situado el receptor. La construcción del mensaje en el lenguaje audiovisual lleva consigo la ponderación de un discurso que permita poner en contacto a los actores de distintas pertenencias; a su vez también reconoce la generación de un espacio donde los códigos pueden compartirse, por medio de una universalidad consensuada (Heras, et. al., 2004).

La construcción del discurso por medio de las narrativas audiovisuales supone el usos de diferentes factores para la construcción del mensaje, y a partir de su implementación en los medios de comunicación audiovisual nos con lleva a profundizar en los elementos semióticos y su estructuración. Los medios audiovisuales son descriptivos por medio de elementos icónicos y auditivos, en ellos se mezclan el uso de los sentidos, por una parte lo visual se compone a partir del uso de imágenes y textos escritos, mientras que lo auditivo se proyecta por medio de la elaboración de un paisaje sonoro donde pueden fluir la enunciación oral, la música o elementos ambiéntales.

Betancur (2006) define al espectador como el actor que a partir de la interacción con el mensaje reconstruye la imagen y la dota de un sentido, es decir un significado, el cual tiene un sentido denotativo por parte del emisor donde está inmersa la intención comunicativa. Si bien el espectador construye la imagen añadiendo su contexto lingüístico al objeto; parte de la propuesta del emisor que representa desde su propia mirada la realidad, reconstruida en un relato audiovisual.

\footnotetext{
${ }^{4}$ Son aquellos textos que poseen una capacidad discursiva, donde se ve determinada a partir de su estructura, temática los cuales tienen la intención de narrar o relatar una serie de sucesos con cualidades reales o ficcionales (Valles, 2008, pp. 31-32).

5 Entiéndase como el diseño de interfaces y plataformas para la interacción digital entre usuarios por medio de dispositivos electrónicos.
} 
En este sentido el relato audiovisual funciona como una estructura cognitiva que da sentido al contexto lingüístico, y que es producido e interpretado mediante el dispositivo y por ende propicia la interacción comunicativa (Herman, 2009). El relato audiovisual tiene cualidades denotativas, por medio de la descripción narrativa de los sucesos los actores interactúan en diferentes niveles de apreciación dándole un valor intrínseco a las particularidades del lenguaje audiovisual implícito.

Reis y Lopes (2002) afirman que el discurso narrativo se sitúa según su función y contexto comunicacional, lo que con lleva a concretarse en distintos soportes expresivos. La imagen discursiva, dando origen al concepto de narrativa audiovisual de Jiménez-García (1993) la conceptualiza como la capacidad que adquiere el lenguaje audiovisual para contar historias; en este sentido el emisor diseña una estrategia comunicativa para transmitir el relato y la sucesión de los hechos.

El estudio del lenguaje audiovisual permite reformular las capacidades y alcances que tienen los dispositivos como mediadores del discurso, introduce a la descripción de su aplicación en los nuevos contextos de comunicación por medio de las plataformas digitales.

El concepto narrativa transmedia proviene del estudio del ecosistema mediático y el reconocimiento de las necesidades digitales de los usuarios, nos permite analizar las prácticas sociales que se generan entorno las dinámicas de interacción inmersas en su construcción y definir cuál es el papel de los usuarios con respecto a las plataformas y su interacción con el relato.

Sáiz (2016) afirma que en la comunicación transmedia, la historia o el mensaje es el núcleo principal, el cual se narra y se expande a través de muchos formatos multimedia. Por medio de múltiples canales se aumenta la participación de la audiencia, y la comprensión; la narrativa transmedia utiliza herramientas digitales para la narración de la historia incluyendo televisión, medios digitales y analógicos, vídeos, medios sociales, móviles, juegos por realidad alternativa y toda una serie de nuevas plataformas que están en constante evolución.

La transmedialidad alude a una especial forma narrativa que se expande en diversos sistemas de significación de tipo verbal, icónico, audiovisual o interactivo, así como en distintos medios como el cine, la televisión, el videojuego, el cómic o el teatro. Long (2007) propone un diagrama para ejemplificar como se construye la narración transmediático:

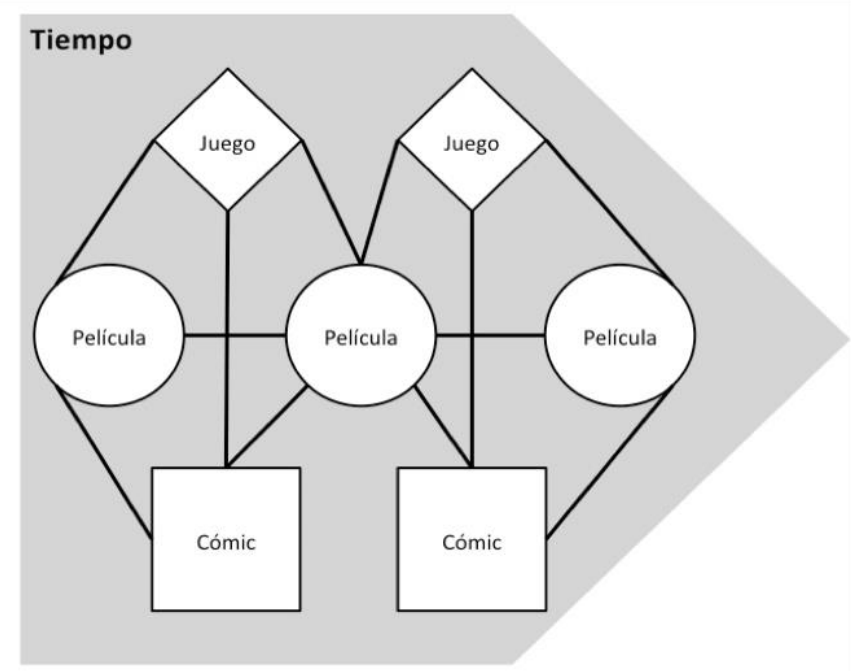

Gráfico 2: narrativa Transmedia.

Fuente: Long, 2007. 
El modelo transmediático de Long nos muestra la reticularidad con la cual se construye la estructura del relato, donde la atemporalidad es un factor determinante en la producción de contenidos, es decir no es necesario visualizar o interactuar en una linealidad temporal para entender el contexto narrativo, cada contenido cuenta con la autonomía de contar un historia la cual se adapta a las características de la plataforma y busca potenciar la capacidad de los usuarios de aportar al construcción o reconstrucción del mismo relato.

A partir de una fragmentación de pantallas los usuarios experimentan una hibridación narrativa y son los mismos los que deciden mediar su experiencia entre uno o varios de estos fragmentos, permitiéndoles explorar el relato transmedia en su totalidad para así completar una experiencia global (Jenkins, 2010). Por otra parte Scolari, conceptualiza el término transmedia, como la oportunidad de explorar nuevos caminos que expandan el ecosistema comunicacional mediante la aplicación de contenidos multimediáticos en las diferentes áreas de consumo multisensorial del hombre; esto en gran medida para redefinir el espacio de consumo de la sociedad y aportar soluciones a las necesidades audiovisuales de los usuarios (Scolari, 2014).

A partir de la construcción de diversos entornos y contextos que se generan por medio de la interacción de los usuarios en las plataformas y las cuales se apoyan de distintos lenguajes y medios surgen nuevas posibilidades de significación estas se sustentan en las tramas, personajes y múltiples desenlaces, pero sin perder los hilos conductores de una matriz original.

La expansión en múltiples plataformas, en la narrativa transmedia necesita de contenidos autónomos pensados en una experiencia autónoma por pare de los usuarios. Esta autonomía de los contenidos debe vincularse en cada plataforma lo que convierte como un punto de acceso al conocimiento de los contenidos (Jenkins, 2010).

Pratten ejemplifica como la construcción narrativa a partir de un diseño multiplataforma a favor de historias individuales pero pertenecientes a un mismo contexto pueden aumentar los niveles de interacción del usuario con respecto a los contenidos y el relato:

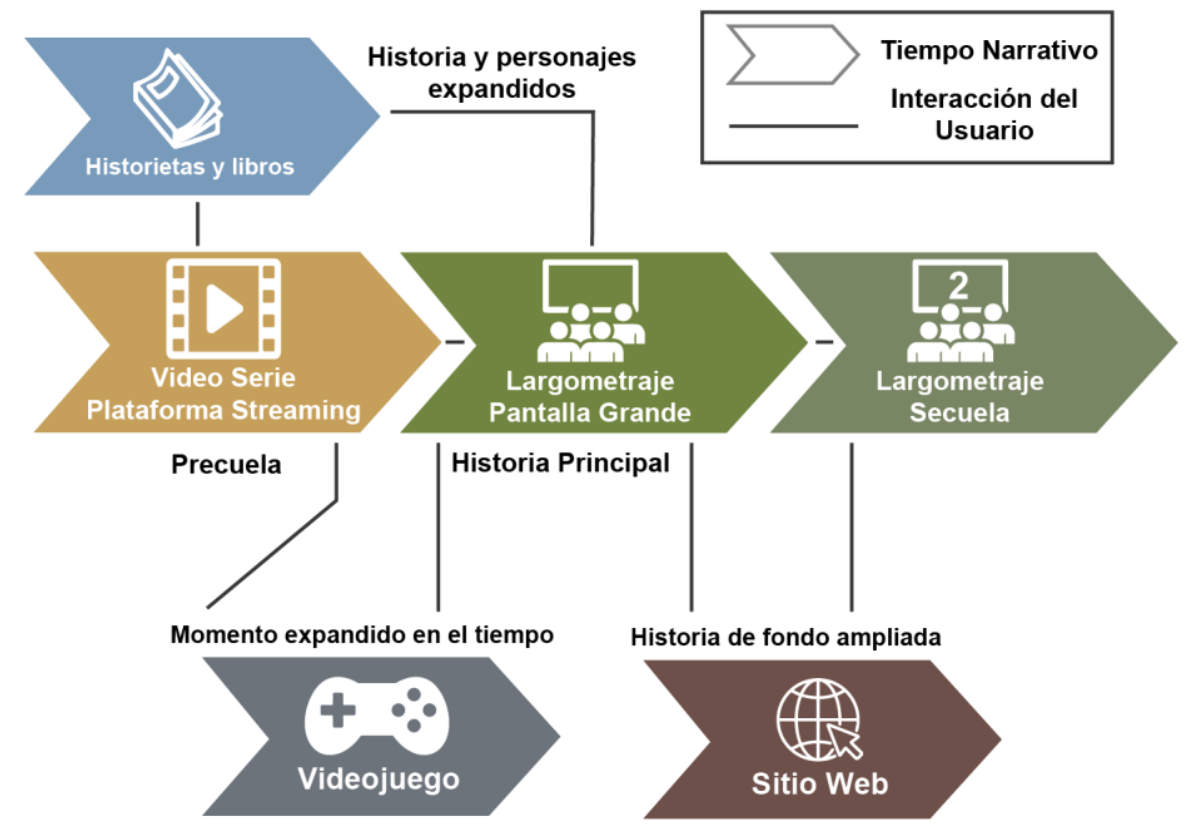

Gráfico 3: construcción narrativa en el modelo transmediático

Fuente: Pratten, 2011. 
Esta red profundiza en el contexto no sólo de los productores también se relaciona directamente con la inmersión de los prosumidores ${ }^{6}$ en la ecología de medios los cuales asumen un rol activo por medio del fomento en la generación de contenidos creativos.

Es decir cada contenido tiene su autonomía narrativa la cual se apropia del relato y lo diversifica por medio de la plataforma, el usuario puede navegar en el universo narrativo, entre un contenido u otro, sin una temporalidad, pero igual seguirá identificando los pilares principales con los cuales se construye la historia.

El modelo transmedia se planea desde la fragmentación narrativa el cual se conforma de un núcleo cognoscitivo donde se adquiere el valor significante por medio de la práctica y conectividad de los usuarios con los contenidos y plataformas, esto debido a su adaptabilidad con diferentes dispositivos y lenguajes. La posibilidad de adaptar los contenidos para diferentes públicos favorece el acceso por parte de los usuarios hacia las narrativas transmedia.

Para Piñeiro y Costa definen que la adaptación de nuevas narrativas como la transmedia implican una transición y mediamorfosis ${ }^{7}$, lo cual sucede gracias a la convergencia entre los medios tradicionales y las TIC; los roles dentro del ámbito de la producción audiovisual lo juegan los productores como los usuarios que ya no solo son espectadores, ahora también producen activamente con los proyectos creativos (Costa \& Piñeiro, 2013).

La narración en el proceso de comunicación digital aporta a las plataformas digitales elementos con fundamento sociocultural; el relato transmedia ratifica la permanencia del discurso en los usuarios por medio de su interacción con el lenguaje audiovisual y el uso de los dispositivos.

La adaptabilidad de los contenidos en múltiples plataformas define la capacidad rizomática que tienen los contenidos al constituirse en diferentes campos y medios de la comunicación audiovisual, esto lleva a que los contenidos pierdan su linealidad espacio-temporal, jugando con la virtualidad de su narrativa (Gordillo, et. al., 2011).

Al vincular contenidos transmediáticos dentro del ecosistema digital audiovisual se pueden abarcar diversos entornos mediáticos, a través del fomento de la conectividad e interactividad de los usuarios enlazando las actividades diarias a la par del consumo contenidos digitales se podría aumentar la capacidad significativa del mensaje.

\subsubsection{Narrativas transmediáticas como herramientas para fortalecer la apropiación social del conocimiento}

La apropiación social del conocimiento mediante herramientas digitales y dispositivos tecnológicos puede dar aportes sustanciales al análisis del proceso de comunicación digital por parte de los usuarios, esto con la finalidad de acércanos a un análisis de los procesos significativos que se establecen en el acto comunicativo.

\footnotetext{
${ }^{6}$ Recordemos que el término prosumidor es adaptado del inglés prosumers, acrónimo que surge como resultado de combinar la palabra producer - productor y consumer - consumidor (Carmona, 2008).

${ }^{7}$ La transformación de los medios de comunicación que generalmente es resultado de la interacción compleja entra las necesidades percibidas, las presiones políticas y de la competencia, y de las innovaciones sociales y tecnológicas. La mediamorfosis no se limita a la transformación de una cosa en otra. El avance tecnológico y la rapidez de aceptación que logran estos fenómenos por parte de la gente no significa que debamos ignorar los hábitos, arraigos y el tiempo que los usuarios precisan para adoptar las nuevas propuestas de los medios (Filder, 1998, pp. 21-22).
} 
Las narrativas transmedia por medio de la fragmentación del relato puede romper las barreras que se establecen entre diversos discursos ya que estas se fundamentan en la idea de generar contenidos no sólo para diversas plataformas sino también para diversos públicos.

La finalidad de narrar por medio de los dispositivos tecnológicos permite que los usuarios se vean representados y representen la realidad partir de su interacción Este tipo de narraciones que carecen de una linealidad permiten dotar de elementos diversos al relato, donde los usuarios pueden aportar por medio de la participación una mirada distinta de los hechos y a su vez generar conocimiento.

Chomon y Busto afirman que el proceso comunicativo ha cambiado, tanto el emisor como el receptor ahora tienen la capacidad de intercambiar sus papeles, el resultado de ello es un proceso complejo y continuo (Chomon \& Busto, 2017). Las narrativas transmedia se centran en estrategias que buscan la propagación de los contenidos de una manera equitativa donde usuarios y realizadores innoven en el sentido de compartir la información y contenidos.

\section{Conclusiones}

Las narrativas transmedia como herramienta para la apropiación social del conocimiento vinculan a los usuarios con espacios democráticos de interacción, donde la información juega un papel fundamental en la transferencia del conocimiento, pero no es hasta que la interacción sucede desde una correspondencia de todos los actores que se construye el espacio democrático y se ve reflejado el conocimiento de manera práctica mejorando la calidad de vida de los usuarios.

La apropiación social del conocimiento con lleva un alto nivel de significación para los usuarios y debería ser el fin común de todo proceso de comunicación que permita a los usuarios ventanas de oportunidad para el desarrollo. Desde diversos ámbitos el uso de la tecnología como mediador del conocimiento puede dar apertura nuevos espacios de socialización donde prevalezca el sentido equitativo del uso de la información y los dispositivos tecnológicos.

\section{Referencias}

Aguado-Terrón, J. M., y Martínez-Martínez, I. J. (2009). De la Web social al Móvil 2.0: el paradigma 2.0 en el proceso de convergencia mediática de la comunicación móvil. El profesional de la información, 18(2).

Betancur, J. L. R. (2006). Mesa 11: Narrativas Audiovisuales. Razón y Palabra, 11(49).

Calvo, S., Oliva, M., y Villa, S. (2018). Web 2.0 y tratamiento informativo en las principales revistas españolas de divulgación científica y de la pseudociencia. Revista Latina de Comunicación Social, (73), 293-316.

Carmona, O. I. (2008). El prosumidor. El actor comunicativo de la sociedad de la ubicuidad. Palabra clave, 11(1), 2.

Carrera, P. (2013). Transmedialidad y ecosistema digital/Transmediality in Digital Environments. Historia y comunicación social, (18), 535-545.

Cebrián Herreros, M. (2009). Nuevas formas de comunicación: cibermedios y medios móviles. Comunicar, 17(33). 
RLCS, Revista Latina de Comunicación Social, 77, 357-372

[Investigación] DOI: 10.4185/RLCS-2020-1462 | ISSN 1138-5820 | Año 2020

Chomón-Serna, J. M., y Busto-Salinas, L. (2018). Ciencia y transmedia: Binomio para la divulgación científica. El caso de atapuerca. El profesional de la información, 27(4).

Costa-Sánchez, C. Piñeiro-Otero, T. (2013). Estrategias de comunicación multimedia.

Fidler, R. (1998). Mediamorfosis: comprender los nuevos medios. Granica.

Freitas, C., y Castro, C. (2010). Narrativas audiovisuales y tecnologías interactivas. Revista Estudios Culturales, (5), 19-42.

Gordillo, I., Guarinos, V., Checa, A., Ramírez Alvarado, M., Jiménez-Varea, J., López Rodríguez, F., y Pérez Gómez, M. A. (2011). Hibridaciones de la hipertelevisión: información y entretenimiento en los modelos de infoentertaiment. Revista comunicación, 1(9), 93-106.

Heras, A. I., Bergesio, L. y Burin, D. (25-27 de Agosto de 2004). Trabajo etnográfico sociolinguísticainteraccional y comunicación visual en la generación y análisis de datos en lenguajes diversos. IV Jornadas de Etnografía, CAS, IDES. Buenos Aires, Argentina.

Herman, D. (2009). The Third Element; or, How to Build a Storyworld, en John Willey y Sons Ltd., Malden, Basic Elements of Narrative, (pp. 105-136).

Islas-Carmona, O. (2015). La ecología de los medios: metadisciplina compleja y sistémica. Palabra clave, 18(4), 1057-1083. https://www.doi.org/10.5294/pacla.2015.18.4.5

Iznaola, R. (2005). ¿Qué significa multimedia? Reflexión Académica en Diseño y Comunicación, 6(VI). Facultad de Diseño y Comunicación - Universidad de Palermo.

Jódar, J. (2010). La era digital: nuevos medios, nuevos usuarios y nuevos profesionales. Razón y Palabra, (71).

Jenkins, H. (2010). Transmedia storytelling and entertainment: An annotated syllabus. Continuum, 24(6), 943-958.

Jiménez, J. G. (1993). Narrativa audiovisual (Vol. 33). Anaya-Spain.

Long, G. A. (2007). Transmedia Storytelling. Bussines, aesthetics and prodyuction at the Jim Henson Company (Trabajo final de máster en Science in comparative media Studies). Massachusetts Institute of Techonology.

Manovich, L. (2005). El lenguaje de los nuevos medios de comunicación: la imagen en la era digital. Paidós.

Martín-Barbero, J., \& Rey, G. (1999). Los ejercicios del ver: hegemonía audiovisual y ficción televisiva (Vol. 2). Gedisa.

McLuhan, M. (1998). La galaxia gutenberg. Círculo de Lectores.

Melero, R., San Miguel, H., y Javier, F. (2014). Acceso abierto a los datos de investigación, una vía hacia la colaboración científica. Revista española de documentación científica, 37(4). 
Morin, E. (2000). Introducción al pensamiento complejo. Gedisa.

Phillippi, M., y Avendaño, C. (2011). Empoderamiento comunicacional: competencias narrativas de los sujetos. Comunicar, (36), 61-68. https://www.doi.org/10.3916/C36-2011-02-06

Pratten, R. (2011). Getting started with transmedia storytelling.

Reis, C., \& Lopes, A. C. M. (1996). Diccionario de narratología. Ediciones colegio de España.

Sáiz, C. (2016). Reinvención del periodismo en el ecosistema digital y narrativas transmedia. adComunica, (12), 163-182.

Sánchez-Torres, J. M., González-Zabala, M. P., \& Muñoz, M. P. S. (2012). La sociedad de la información: génesis, iniciativas, concepto y su relación con las TIC. Revista UIS Ingenierías, 11(1), 113-128.

Scolari, C. (2012). Comunicación digital: recuerdos del futuro. El Profesional de la Información. 21(4), 337-340.

Scolari, C. (2014). Narrativas transmedia: nuevas formas de comunicar en la era digital. Anuario AC/E de cultura digital, 2014, 71-81.

Valles, J. (2008). Teoría de la narrativa. Una perspectiva sistemática. Iberoamericana.

Yepes, J. (2011). Apuntes sobre comunicación digital. Revista Virtual Universidad Católica del Norte, 1(19).

Vessuri, H. (2002). Ciencia, tecnología y desarrollo: una experiencia de apropiación social del conocimiento. Interciencia, 27(2), 88-92.

\section{AUTORAS:}

\section{Ariadna Jauregui Caballero}

Profesora e investigadora con interés en las líneas de investigación: ecología mediática, narrativas Transmedia y crossmedia, comunicación digital, TIC y comunicación científica. Estudio el Doctorado en Ciencias Sociales y Maestría en Diseño por la Universidad Autónoma del Estado de México.

ajaureguic@uaemex.mx

ResearchGate: https://www.researchgate.net/profile/Ariadna_Jauregui

\section{Claudia Ortega Ponce}

Doctorado en Ciencias Sociales y Maestría en Sociología por la Universidad Autónoma del Estado de México en el área de Sociología de la Ciencia y la Tecnología. Actualmente es ProfesoraInvestigadora de la Facultad de Ciencias Políticas y Sociales de la UAEM. En la tarea de investigación forma parte del cuerpo académico "Sociotecnología, Gobierno y Comunicación” el cual integra dos Líneas de Generación y Aplicación del Conocimiento: Línea 1. Gobierno, conocimiento y sociotecnología; Línea 2. Procesos Comunicativos y Representaciones Sociales. Respecto a la docencia, imparte las asignaturas: Epistemología de la investigación social, Filosofía 
RLCS, Revista Latina de Comunicación Social, 77, 357-372

[Investigación] DOI: 10.4185/RLCS-2020-1462 | ISSN 1138-5820| $\mid$ Año 2020

de la ciencia, Metodología de las ciencias sociales, Teoría social y Sociología de la tecnociencia en los niveles de pregrado y posgrado.

cop@uaemex.mx

ResearchGate: https://www.researchgate.net/profile/Claudia_Ortega4

Google Académico: https://scholar.google.es/citations?hl=es\&user=xyKSKekAAAAJ 